\title{
IN VITRO ANTIOXIDANT AND CYTOTOXIC PROPERTIES OF FUCOIDAN FROM THREE INDIAN BROWN SEAWEEDS
}

\section{SREEKALA KANNIKULATHEL GOPIDAS, NAGARAJ SUBRAMANI*}

Centre for Advanced Studies in Botany, University of Madras, Chennai, Tamil Nadu, India. Email: nagalilly@gmail.com

Received: 16 May 2019, Revised and Accepted: 09 July 2019

\begin{abstract}
Objective: In the present study, fucoidan extracted from three brown algae, Sargassum wightii, Turbinaria ornata, and Padina tetrastromatica, was purified, characterized, and evaluated for antioxidant and cytotoxic properties.

Methods: Algal powders were sequentially extracted with five solvents based on polarity and residue was subjected to acidic extraction. The filtrates were precipitated for alginates, and resultant supernatant was precipitated for fucoidan. The precipitate was centrifuged; pellet dialyzed and lyophilized to yield crude fucoidan, which was purified by diethylaminoethyl cellulose chromatography and characterized by biochemical tests and Fourier-transform infrared (FT-IR) spectrometry. Solvent extracts and fucoidans were subjected to 2,2-diphenyl-1-picrylhydrazyl assay. Fucoidans were subjected to trypan blue cytotoxicity assay.
\end{abstract}

Results: Antioxidant activity was highest in methanol extracts and Padina crude fucoidan, while lowest in hexane extracts and purified Sargassum fucoidan. Sargassum yielded the highest amount of fucoidan (7.14\%). Total carbohydrates increased as Sargassum> Padina $>$ Turbinaria, sulfates as Padina $>$ Turbinaria $>$ Sargassum, and protein content was $0.16 \pm 0.001 \%$. Cytotoxicity increased in a dose-dependent manner; the highest and lowest for Padina at $200 \mathrm{mg} \mathrm{mL}^{-1}(40 \%)$ and $10 \mathrm{mg} \mathrm{mL}^{-1}$ (4\%), respectively. Antioxidant and cytotoxic properties exhibited a positive correlation with sulfate content. FT-IR spectral values were characteristic to fucoidan.

Conclusion: Fucoidans from the three algae effectively scavenged free radicals and showed good cytotoxic activity. There was a positive correlation between sulfate content and bioactivity of fucoidans, supporting its structure-function relationship. Thus, extracts and fucoidans from these algae are found to be potential candidates for pharmacological applications.

Keywords: Antioxidant, Cytotoxic, Fucoidan, Brown algae, Sargassum wightii, Turbinaria ornata, Padina tetrastromatica

(C) 2019 The Authors. Published by Innovare Academic Sciences Pvt Ltd. This is an open access article under the CC BY license (http://creativecommons. org/licenses/by/4. 0/) DOI: http://dx.doi.org/10.22159/ajpcr.2019.v12i9.34164

\section{INTRODUCTION}

Fucoidans refer to a class of fucose-containing sulfated cell wall polysaccharides with complex, heterogeneous, and diverse chemical composition and structure. These polysaccharides in common have a backbone of $(1 \rightarrow 3)$-linked $\alpha$-L-fucopyranosyl residues or of alternating $(1 \rightarrow 3)$ - and $(1 \rightarrow 4)$-linked $\alpha$-L-fucopyranosyl residues but may also include sulfated galactofucans with backbones of $(1 \rightarrow 6)-\beta$-D-galacto and/or $(1 \rightarrow 2)-\beta$-D-mannopyranosyl units with fucose. It contains L-fucose as main sugar unit and varying amounts of minor monosaccharides such as D-galactose, D-xylose, D-glucose, D-mannose, D-glucuronic acid, and D-uronic acid along with other substitutions [1]. A wide range of biological activities has been reported for fucoidan extracted from different brown seaweeds, namely, antioxidant [2], anti-inflammatory [3], anticancer [4,5], immunomodulatory [6], anticoagulant [7], antithrombotic [8,9], antiviral [10], antiarthritic [11], antiobesity [12], and antiallergic [12] effects among many others. Several methods are available for fucoidan extraction such as hot water, acidic, alkaline [13], microwaveassisted [14], ultrasound-assisted [15], and enzymatic methods [16], purification, and characterization of fucoidan [17]. The molecular weight, structure, chemical composition, and bioactivity of fucoidan depend on these methods as well as the species, location, and season of the collection [18].

Oxidative stress and the release of free radicals are one of the major causes for several disease conditions such as rheumatism, cancers, aging, neural disorders, ulcerative colitis, and cardiovascular disorders.
Free radicals released evoke inflammatory responses by damaging the important macromolecules and membrane system of cells. Antioxidants can neutralize these free radicals, thereby protecting from such diseases. The commercially available synthetic antioxidants are found to exert harmful effects, and hence, there is a quest for exploring natural antioxidants. Fucoidan derived from many brown seaweeds has been reported to have an excellent antioxidant property [11].

The World Health Organization, through its cancer research agency, International Agency for Research on Cancer, has conducted research and reported that cancer is the second leading cause of death globally and was responsible for 8.8 million deaths in 2015. Globally, nearly 1 in 6 deaths is due to cancer [19]. Nowadays, a combination of therapies is used to treat cancers, wherein chemotherapy is the most commonly employed and it has been found that the synthetic chemo drugs used to affect both cancer and normal healthy cells alike, causing multiple side effects. Natural alternatives like fucoidan from various brown algae have shown promising effects against different types of cancers, while also causing no or minimum side effects and, in turn, improving the overall health and life expectancy of the individuals [20].

In this context, the present study is aimed at utilizing the three brown algal species, Sargassum wightii Greville, Turbinaria ornata (Turner) J. Agardh, and Padina tetrastromatica Hauck for the extraction, purification, and characterization of fucoidan, and to evaluate its antioxidant and cytotoxic properties as a natural and safe therapeutic agent. 


\section{MATERIALS AND METHODS}

\section{Materials}

Analytical grade chemicals were used in all the studies. The chemicals and analytical grade reagents were purchased from HiMedia and Sisco Research Laboratories, Mumbai and Chennai, India.

\section{Seaweed sample collection and identification}

Fresh, matured biomass of three brown seaweeds S. wightii, T. ornata, and $P$. tetrastromatica was collected from the coast of Kilakarai (latitude $9^{\circ} 14 \mathrm{~N}$ and longitude $78^{\circ} 50 \mathrm{E}$ ) in Gulf of Mannar located in Southeast coast of Tamil Nadu, India. The collected seaweeds were identified and documented in Centre for Advanced Studies in Botany, University of Madras, Chennai, Tamil Nadu, India. The algae were washed thoroughly in seawater, followed by tap water until all epiphytes, sand particles, associated fauna, and other extraneous materials were removed. Seaweeds were shade dried for 5 days, followed by oven drying (Sandy Scientific Instruments and Co., Chennai, India) for $12 \mathrm{~h}$ at $60^{\circ} \mathrm{C}$, and the dry weight of the sample was determined. The material was hand crushed and ground using electronic mixer grinder (Philips HL 1643/04 Vertical Mixer Grinder, India). The powder was processed further for the extraction of sulfated polysaccharide fucoidan.

\section{Extraction of sulfated polysaccharide fucoidan}

The extraction of fucoidans was done according to a modified protocol of Suresh etal.,2013 [21]. A total of $50 \mathrm{~g}$ of each algal powder were sequentially extracted in a Soxhlet apparatus, with $700 \mathrm{~mL}$ of five different solvents such as hexane, chloroform, ethyl acetate, acetone, and methanol, in the increasing order of polarity. The process was continued until the extract turned colorless in each solvent, to ensure the complete decoloration and defatting of the dry biomass. This biomass was then dispersed in $2 \mathrm{~L}$ of $0.1 \mathrm{M} \mathrm{HCl}(\mathrm{pH} 2.0-2.5)$ and boiled at $100^{\circ} \mathrm{C}$ for $4 \mathrm{~h}$ twice, with constant stirring. The boiled solution was filtered through a sieve, filter paper as well as Whatman No. 1 filter paper, and the filtrates were pooled. Equal volumes of $2 \% \mathrm{Na}_{2} \mathrm{CO}_{3}$ followed by $1 \% \mathrm{CaCl}_{2}$ were added to the filtrate and kept at $4^{\circ} \mathrm{C}$ overnight to precipitate the alginates. The resultant precipitate was centrifuged (HERMLE Labortechnik GmbH, Z 32 HK, Germany) at $3900 \times \mathrm{g}$ for $10 \mathrm{~min}$, at $28^{\circ} \mathrm{C}$. The supernatants were pooled, added with double the volume of pre-cooled acetone, and kept at $4^{\circ} \mathrm{C}$ overnight, to precipitate out the fucoidan. The precipitate was centrifuged at $3900 \times \mathrm{g}$ for $10 \mathrm{~min}$, at $28^{\circ} \mathrm{C}$. The pellet was collected, dissolved in water, and dialyzed against glass distilled water using a membrane (Molecular Weight Cutoff, [MWCO] 14,000; HiMedia Laboratories Pvt. Ltd., Mumbai, India) at $18^{\circ} \mathrm{C}$ for 2 days. Then, the dialysate was centrifuged at 15,680 $\times \mathrm{g}$ for $10 \mathrm{~min}$, at $28^{\circ} \mathrm{C}$, and the supernatant was lyophilized (Mini-Lyodel, Delvac Pumps Pvt. Ltd., Chennai, India). This yielded the partially purified fucoidan or crude fucoidan.

\section{Purification of fucoidan by ion-exchange chromatography}

The crude polysaccharide weighing $500 \mathrm{mg}$ was redissolved in $5 \mathrm{~mL}$ glass distilled water and loaded on to diethylaminoethyl (DEAE) cellulose column (HiMedia Laboratories Pvt. Ltd., Mumbai, India) $(25 \mathrm{~cm} \times 4 \mathrm{~cm})$, previously washed with $25 \mathrm{~mL}$ of $4 \mathrm{M} \mathrm{NaCl}$, glass distilled water, and then $0.1 \mathrm{M}$ sodium phosphate buffer ( $\mathrm{pH}$ 7.2). This was followed by step-wise elution with solutions of $0.1 \mathrm{M}$ sodium phosphate buffer, $0.2,0.7$, and $1.5 \mathrm{M} \mathrm{NaCl}$. The flow rate was maintained at $60 \mathrm{~mL} \mathrm{~h}^{-1}$. Eluants of $10 \mathrm{~mL}$ each were collected, and the carbohydrate content was determined by the phenol-sulfuric acid method (Dubois et al., 1956), using D-glucose as the standard. Three fractions were obtained, $\mathrm{F}_{1}, \mathrm{~F}_{2}$, and $\mathrm{F}_{3}$. The fractions containing the higher amount of carbohydrates were pooled, added with double the volume of pre-cooled acetone, and kept at $4^{\circ} \mathrm{C}$ overnight, to precipitate fucoidan. The precipitated fucoidan was centrifuged at $15680 \times \mathrm{g}$ for $10 \mathrm{~min}$, at $28^{\circ} \mathrm{C}$ and the pellet was redissolved and dialyzed in glass distilled water for 2 days and lyophilized. This yielded the purified fucoidan which was stored at $4^{\circ} \mathrm{C}$ for further study.

\section{Characterization of fucoidan}

Chemical analyses

The total sugar was determined by the phenol-sulfuric acid method using L-fucose as the standard [22]. The sulfate content was measured using the $\mathrm{BaCl}_{2}$-gelatine method using potassium sulfate as the standard [23]. The protein content was estimated by Bradford's method with bovine serum albumin as the standard [24]. The cysteine $\mathrm{HCl}$-sulfuric acid method was performed as a qualitative test for fucoidan [25].

\section{Fourier-transform infrared (FT-IR) spectroscopy analysis}

The functional groups of fucoidan were analyzed in the FT-IR spectrophotometer (PerkinElmer System One, PerkinElmer (India) Pvt. Ltd., Maharashtra, India). The sample (2 mg) was ground with $100 \mathrm{mg}$ potassium bromide and pressed into the disc under vacuum. The infrared spectrum was recorded over a range of $4000-450 \mathrm{~cm}^{-1}$, using 64 scans at a resolution of $4 \mathrm{~cm}^{-1}$.

\section{In vitro antioxidant activity}

\section{2,2-diphenyl-1-picrylhydrazyl (DPPH) radical scavenging assay}

The antioxidant activity of samples was carried out according to the procedure available [26]. Different volume levels of standard ascorbic acid and test samples $(100,200,300,400$, and $500 \mu \mathrm{L})$ were taken into test tubes and made $1 \mathrm{~mL}$ each dose level by dilution with the respective solvent in which it was extracted, followed by dilution up to $3 \mathrm{~mL}$. Further, $150 \mu \mathrm{L}$ DPPH solution was added to each test tube. Absorbance was taken at $516 \mathrm{~nm}$ in ultraviolet (UV)visible spectrophotometer (Hitachi U2900, UV-vis double-beam spectrophotometer, Hitachi High Technologies America, Inc.) after 15 min using methanol as blank. About $150 \mu \mathrm{L}$ of DPPH solution was added to $3 \mathrm{~mL}$ methanol and absorbance was taken immediately at $516 \mathrm{~nm}$ for control reading. The free radical scavenging activity (FRSA) or percentage antiradical activity was calculated using the following equation:

$\%$ Antiradical activity $=\{($ Control absorance-Sample absorance $) \div$ Control absorance $\} \times 100$

Each experiment was carried out in triplicate and the results are expressed as mean percentage antiradical activity \pm standard deviation.

\section{In vitro cytotoxicity analysis}

Trypan blue exclusion method

The fucoidan was studied for a short-term in vitro cytotoxicity using Dalton's lymphoma ascites (DLA) cells. The tumor cells aspirated from the peritoneal cavity of tumor-bearing mice were washed thrice with phosphate-buffered saline (PBS) or normal saline. Cell viability was determined by trypan blue exclusion method. Viable cell suspension $\left(1 \times 10^{6}\right.$ cells in $\left.0.1 \mathrm{~mL}\right)$ was added to tubes containing various concentrations $\left(10,20,50,100\right.$, and $\left.200 \mathrm{mg} \mathrm{mL}^{-1}\right)$ of the test compounds dissolved in dimethyl sulfoxide, and the volume was made up to $1 \mathrm{~mL}$ using PBS. Control tube contained only cell suspension. These assay mixtures were incubated for $3 \mathrm{~h}$ at $37^{\circ} \mathrm{C}$. Further, the suspension of cells was mixed with $0.1 \mathrm{~mL}$ of $1 \%$ trypan blue and kept for 2-3 min before loading on a hemocytometer. Dead cells took up the blue color of trypan blue while live cells did not take up the dye. The number of stained and unstained cells was counted separately. The percentage of cytotoxicity was calculated by the following equation:

$\%$ Cytotoxicity $=\{$ (No. of dead cells $) \div($ No of live cells + No of dead cells ) $\} \times 100$

Table 1: The weight (in gram) of solvent extracts obtained from the three algal species

\begin{tabular}{lllll}
\hline S. No. & Solvents & $\begin{array}{l}\text { Sargassum } \\
\text { wightii }(\mathrm{g})\end{array}$ & $\begin{array}{l}\text { Turbinaria } \\
\text { ornata }(\mathrm{g})\end{array}$ & $\begin{array}{l}\text { Padina } \\
\text { tetrastromatica }(\mathrm{g})\end{array}$ \\
\hline 1. & Hexane & 1.04 & 0.92 & 0.25 \\
2. & Chloroform & 1.05 & 1.42 & 0.98 \\
3. & Ethyl acetate & 0.48 & 0.43 & 0.36 \\
4. & Acetone & 0.15 & 0.27 & 0.12 \\
5. & Methanol & 0.37 & 0.45 & 0.34 \\
\hline
\end{tabular}




\section{RESULTS}

Depigmenting and defatting (solvent extraction) of algal samples The powdered algal samples of S. wightii, T. ornata, and P. tetrastromatica were extracted with five solvents hexane, chloroform, ethyl acetate, acetone, and methanol sequentially in the increasing order of their polarities, to obtain crude extracts (Fig. 1). The amount of solvent extracts obtained from the three algae is given in Table 1. The sequential solvent extraction was found to be a very effective pretreatment method for eliminating all possible contaminants before acidic extraction of the algae.

\section{Extraction, purification, and characterization of fucoidan}

The algal powders post-solvent extraction was subjected to hot acidic water extraction, precipitated with acetone, dialyzed, and lyophilized. From the crude fucoidans thus obtained, the one that yielded the highest amount of total carbohydrates, i.e. Sargassum, was purified by DEAE column chromatography to obtain three fractions $\mathrm{F}_{1}, \mathrm{~F}_{2}$, and $\mathrm{F}_{3}$ (Fig. 2). The fucoidans retained in the dialysis membrane (MWCO 14,000) were considered to be of the molecular weight of $14 \mathrm{kD}$ [27]. The yield of crude fucoidan obtained was highest in S. wightii followed by P. tetrastromatica and T. ornata (Table 2) while the yield of purified fucoidan or the column fractions $\mathrm{F}_{1}$ (corresponding to $0.2 \mathrm{M} \mathrm{NaCl}$ elution), $\mathrm{F}_{2}$ (corresponding to $0.7 \mathrm{M} \mathrm{NaCl}$ elution), and $\mathrm{F}_{3}$ (corresponding to $1.5 \mathrm{M} \mathrm{NaCl}$ elution) of $S$. wightii was approximately $20 \mathrm{mg}$. The total carbohydrates content was the highest in S. wightii followed by $P$. tetrastromatica and T. ornata, while the sulfates content was the highest in Padina followed by Turbinaria and Sargassum. The protein content was $0.1 \%$ in all the samples. The percentage of total sugars, proteins, and sulfates in the purified fraction, $\mathrm{F}_{3}$ of Sargassum is also given (Table 2). In the cysteine $\mathrm{HCl}$-sulfuric acid test for fucose, the development of a greenish-yellow color that persisted for $24 \mathrm{~h}$ indicated the presence of L-fucose in all the crude as well as purified sample solutions of fucoidan.

\section{FT-IR analysis of fucoidans}

FT-IR spectra of the three crude fucoidan samples, as well as the purified fraction F3 of $S$. wightii, showed characteristic absorption bands of sulfated polysaccharides (Figs. 3 and 4). The broad, intense bands in the regions of $3600-3200 \mathrm{~cm}^{-1}$ (i.e. $3434 \mathrm{~cm}^{-1}, 3428 \mathrm{~cm}^{-1}, 3409 \mathrm{~cm}^{-1}$, and $3433 \mathrm{~cm}^{-1}$ here) can be attributed to the stretching vibrations of the hydroxyl group (-OH) common to all polysaccharides [13]. Stretch bands at $2926 \mathrm{~cm}^{-1}$ and $2925 \mathrm{~cm}^{-1}$ indicated $\mathrm{C}-\mathrm{H}$ stretching of the pyranoid ring and C- 6 group of fucose and galactose [28]. The bands at 2138 and $2144 \mathrm{~cm}^{-1}$ corresponds to $\mathrm{C}-\mathrm{H}$ stretching [8,29]. Asymmetric and symmetric stretching vibrations of the carboxylic group (-COO-) gave characteristic bands at $1638,1632,1611$, and $1644 \mathrm{~cm}^{-1}$ and bands at 1423,1425 , and $1422 \mathrm{~cm}^{-1}$, respectively. It thus proves the acidic nature of polysaccharides and hence the existence of uronic acids [30,31]. The $1365 \mathrm{~cm}^{-1}$ in the FT-IR graph of $\mathrm{F}_{3}$ fraction, on the other hand, indicated the presence of sulfate groups [32] and $1151 \mathrm{~cm}^{-1}$ indicated hemiacetal stretching [31]. The signal at $1251 \mathrm{~cm}^{-1}$ indicates primary
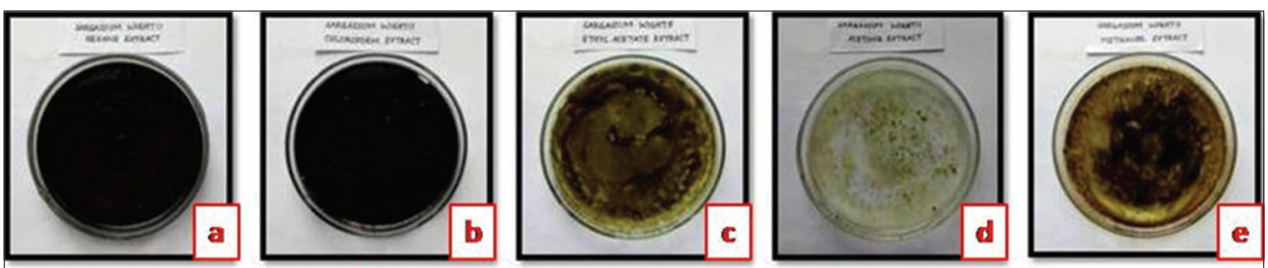

(i). Solvent extracts of Sargassum wightï
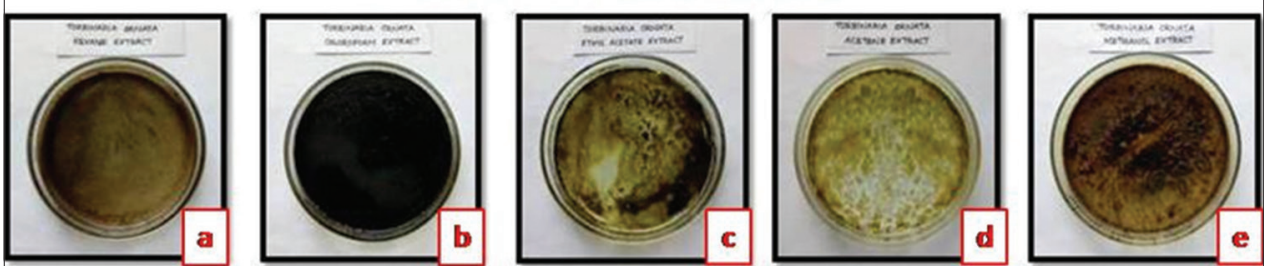

(iii). Solvent extracts of Turbinaria ornata
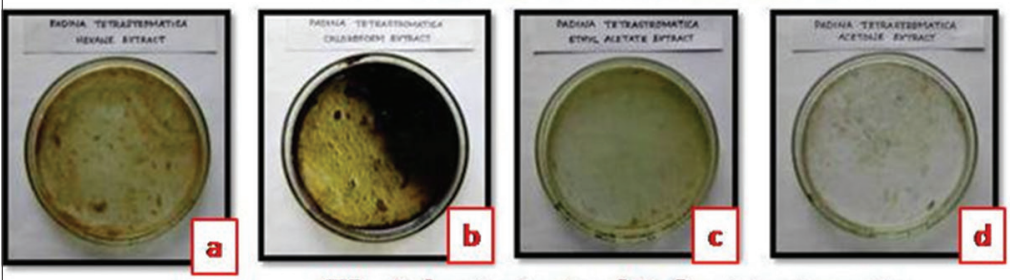

-

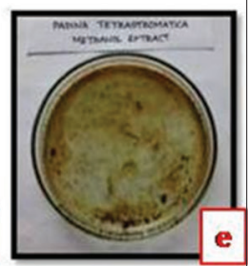

(iii). Solvent extracts of Padina tetrastromatica

Fig. 1: Five solvent extracts of the three brown algae; (i) solvent extracts of Sargassum wightii, (ii) solvent extracts of Turbinaria ornata, and (iii) solvent extracts of Padina tetrastromatica; (a) hexane extract, (b) chloroform extract, (c) ethyl acetate extract, (d) acetone extract, and (e) methanol extract

Table 2: Percentage yield and composition of fucoidans extracted

\begin{tabular}{llll}
\hline Type of fucoidan & \% yield & Total carbohydrates (\%) & Sulfates (\%) \\
\hline SCF & 7.14 & $42.19 \pm 0.3$ & $3.11 \pm 0.4$ \\
TCF & 0.94 & $29.69 \pm 0.7$ & $4.76 \pm 0.3$ \\
PCF & 4.28 & $33.13 \pm 0.2$ & $6.70 \pm 0.1$ \\
F & 0.04 & $19.72 \pm 0.1$ & $4.32 \pm 0.2$ \\
\hline
\end{tabular}

SCF: Sargassum crude fucoidan, TCF: Turbinaria crude fucoidan, PCF: Padina crude fucoidan, $\mathrm{F}_{3}$ : Purified fraction of Sargassum fucoidan. Values are mean \pm standard deviation from three independent tests 


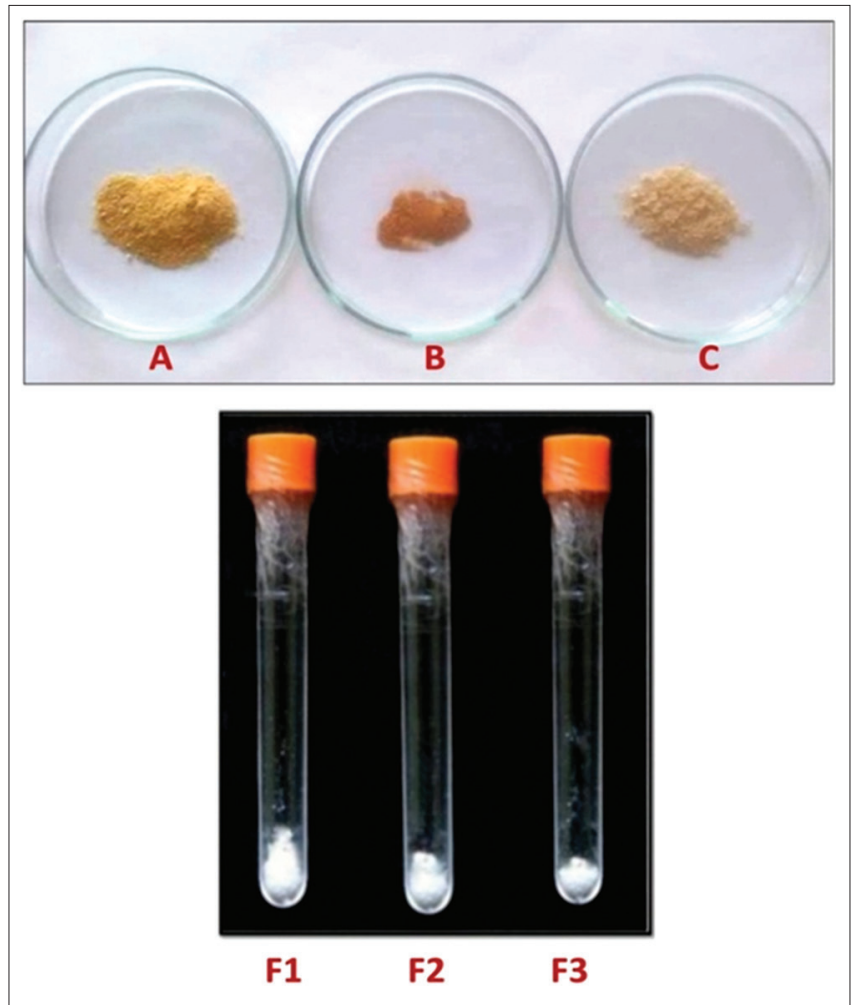

Fig. 2: Crude fucoidan obtained from: A=Sargassum wightii, $\mathrm{B}=$ Padina tetrastromatic , and C=Turbinaria ornat $a$ and purified fractions $\mathrm{F}_{1}, \mathrm{~F}_{2}$, and $\mathrm{F}_{3}$ of Sargassum crude fucoidan

and secondary $\mathrm{O}$-sulfate groups characteristic to marine-sulfated polysaccharides and stands for asymmetric stretching vibrations of sulfate esters $(S=0)[8,28,33]$. Absorption bands at 1054, 1051, and $1062 \mathrm{~cm}^{-1}$ correspond to the stretching vibrations of C-O-C and C-O-H groups [33,34] while the band $1098 \mathrm{~cm}^{-1} \mathrm{in} \mathrm{F}_{3}$ graph corresponds to C-O and C-C stretching vibrations of pyranose ring. Absorption at $898 \mathrm{~cm}^{-1}$ indicated $\alpha$-glycosidic linkages. An absorption peak at $820 \mathrm{~cm}^{-1}$ can be ascribed to the bending vibrations of C-O-S of sulfates at axial C-2 and/ or C-3, C-O-O and complex substitution of $\mathrm{C} 4$ and $\mathrm{C} 6$ monosaccharide units $[33,35]$. From these data, it can be inferred that the fucoidan obtained from the three algae is acidic sulfated polysaccharides with the presence of fucose and galactose as the main monosaccharide units, has uronic acid content and sulfate esters at axial positions.

\section{In vitro antioxidant activity}

The in vitro antioxidant activities of the solvent extracts were evaluated by DPPH scavenging assay. When a solution of DPPH is mixed with that of a substrate $(\mathrm{AH})$ that can donate a hydrogen atom, then this gives rise to the reduced form with the loss of its violet color. Among the five solvent extracts of $S$. wightii, the methanol extract of the concentration of $500 \mathrm{mg} \mathrm{mL}^{-1}$ showed the maximum DPPH scavenging activity of $86.88 \pm 0.29 \%$. The lowest activity observed was $19.88 \pm 0.62 \%$ in the $100 \mathrm{mg} \mathrm{mL}^{-1}$ concentration of hexane extract (Fig. 5a). The maximum activity among solvent extracts of $P$. tetrastromatica observed was $86.52 \pm 1.05 \%$ by the $400 \mathrm{mg} \mathrm{mL}^{-1}$ concentration of methanol extract, and the lowest was $47.35 \pm 0.16 \%$ by the $100 \mathrm{mg} \mathrm{mL}^{-1}$ concentration of hexane extract (Fig. 5b). In case of solvent extracts of T. ornata, the maximum activity was $93.47 \pm 1.28 \%$ in the $400 \mathrm{mg} \mathrm{mL}^{-1}$ concentration of methanol extract, while the lowest was $46.47 \pm 0.36 \%$ in the $100 \mathrm{mg} \mathrm{mL}^{-1}$ concentration of hexane extract (Fig. 5c). There is a linear increase in the DPPH scavenging activity in a dose-dependent manner although some extracts exhibited altered activity with an increase in extract concentration.

The DPPH scavenging assay was also conducted for the crude and purified fucoidans. In all samples, there is an increase in the antioxidant

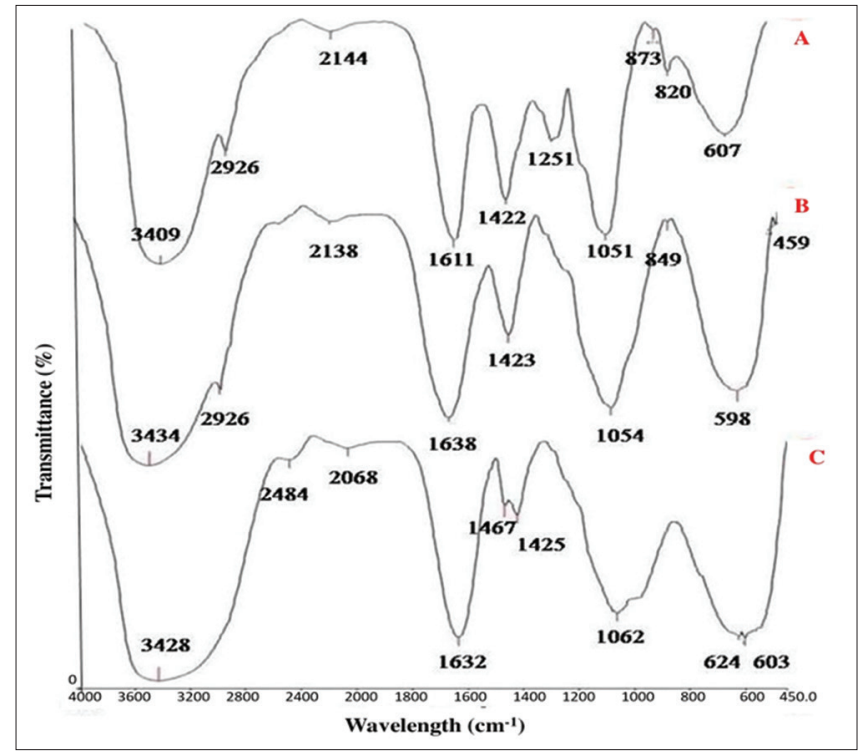

Fig. 3: Fourier-transform infrared spectra of crude fucoidans of (a) Turbinaria ornata, (b) Padina tetrastromatica, and (C) Sargassum wightii

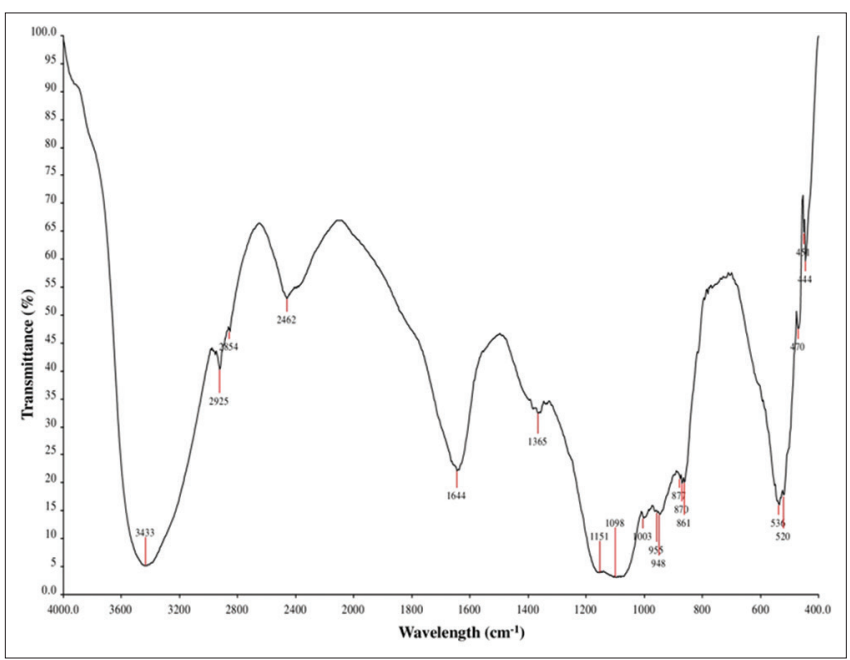

Fig. 4: Fourier-transform infrared spectra of $F_{3}$, the purified fraction of crude fucoidan from Sargassum wightii

activity as the concentration of sample increased. The highest activity was shown by the crude fucoidan of Padina and the lowest by the crude fucoidan from Sargassum (Fig. 5d).

\section{In vitro cytotoxicity analysis of crude and purified fucoidan}

The cytotoxic nature of crude and purified fucoidans was investigated by conducting trypan blue exclusion method of cytotoxicity analysis. The Dalton's ascites lymphoma cells were treated with varying concentrations of the crude and purified fucoidans $\left(10,20,50,100\right.$, and $\left.200 \mathrm{mg} \mathrm{mL}^{-1}\right)$ to observe the following results. The activity was measured as percentage cytotoxicity. The maximum cytotoxicity was exhibited by $200 \mathrm{mg} \mathrm{mL}^{-1}$ of crude fucoidan from Padina (40\%), whereas the least toxicity was observed in the $10 \mathrm{mg} \mathrm{mL}^{-1}$ concentration of Padina. There is an increase in the cytotoxic effect of the fucoidans in a dose-dependent manner. On contrary to this, only the $200 \mathrm{mg} \mathrm{mL}^{-1}$ concentration of Sargassum showed activity, while for all other concentrations, there was no cytotoxicity observed. At very lower concentrations like 10 or $20 \mathrm{mg} \mathrm{mL}^{-1}$, only Padina fucoidan showed some activity. The effect of samples on the cells can be seen in the figures that follow. The dead cells took up the trypan blue dye and can be seen as blue entities against a background of uncolored live cells (Fig. 6). 


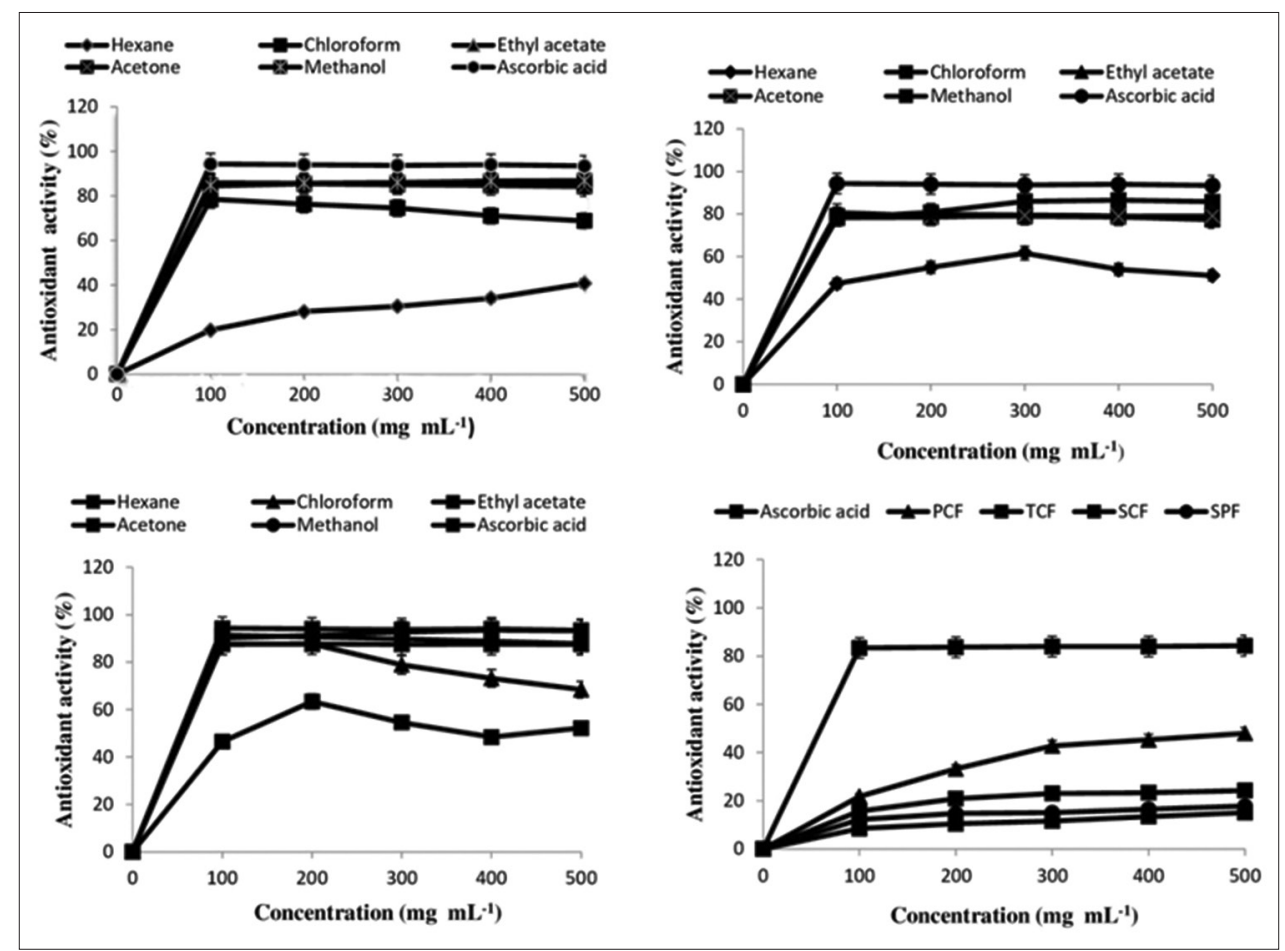

Fig. 5: 2,2-diphenyl-1-picrylhydrazyl radical scavenging activity of (a) Sargassum extracts, (b) Padina extracts, (c) Turbinaria extracts, and

(d) various crude and purified fucoidans. PCF: Padina crude fucoidan, TCF: Turbinaria crude fucoidan, SCF: Sargassum crude fucoidan, and SPF: Sargassum purified fucoidan $\left(\mathrm{F}_{3}\right)$. Values are mean \pm standard deviation from three independent tests

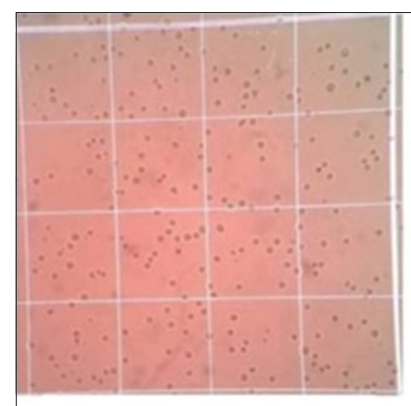

Live DLA cells indicating $0 \%$ toxicity

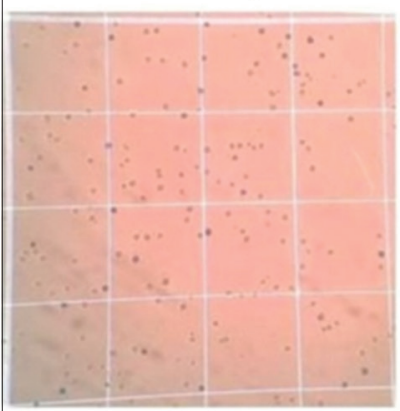

$24 \%$ cytotoxicity (purified Sargassum fucoidan)

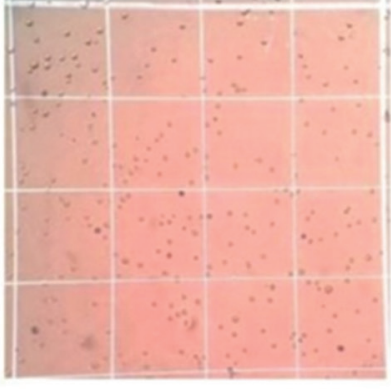

$5 \%$ cytotoxicity (crude Sargassum fucoidan)

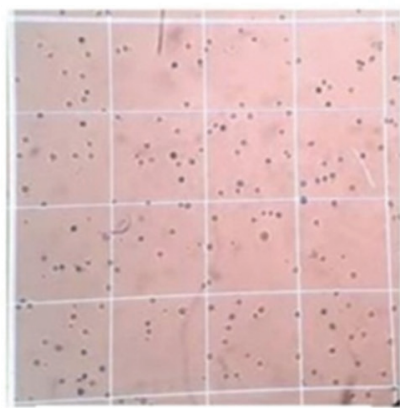

$40 \%$ cytotoxicity (crude Padina fucoidan)

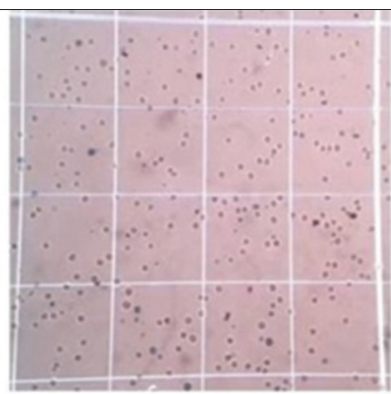

$18 \%$ cytotoxicity (crude Turbinaria fucoidan)

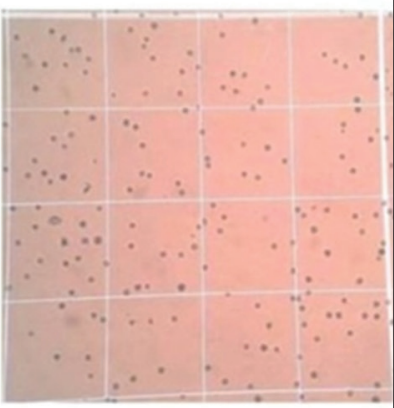

Dead cells denoting $100 \%$ cytotoxicity

Fig. 6: Percentage cytotoxicity of fucoidans on Dalton's ascites lymphoma cells

\section{DISCUSSION}

Fucoidan constitutes about $5-10 \%$ of the dry algal biomass. The composition of fucoidan varies in brown algae with respect to its species, environment, and collection season. Hayakawa and Nagamime (2009) also reported that purified fucoidan contains $<0.1 \%$ of protein contamination. The difference in the previous reports and the current study may be due to the differing habitats, seasons, extraction, and purification methods, and the type of species studied [36]. From the FT-IR data, it was concluded that the fucoidan obtained from the three algae is acidic sulfated polysaccharides with the presence of fucose and galactose as the main monosaccharide units, has uronic acid content and sulfate esters at axial positions. 
A linear increase in the DPPH scavenging activity in a dose-dependent manner was observed in case of both the solvent extracts and fucoidans of the three algae. These results are comparable with those reported $[37,38]$. Reports said that this antioxidant potential of solvent extracts of algae may be attributed to the contents of polyphenols, pigments, flavonoids, and phlorotannins present in them.

Earlier, many reports have discussed the antioxidant, anticancer, cytotoxic, and antiproliferative properties of fucoidan extracted from several brown seaweeds, especially Sargassum. In 2014, Anjana et al. had reported the anticancer effect of the ethanolic extract of $S$. wightii Greville on DLA cells using trypan blue exclusion method [39]. The dose-dependent antioxidant potential of methanolic extract of Sargassum swartzii was also reported and was attributed to the phenolic compounds in the extract [40]. The findings of the present study coincided with this finding. In another report, the $\mathrm{F}_{2}$ fraction of fucoidan from Sargassum plagiophyllum, containing higher sulfate content was found effective against human liver cancer (HepG2) and lung cancer (A549) cell lines [21]. Similar observations were also made in Sargassum polycystum, in which of the four fractions obtained, F2 showed highest yield \%, fucose and sulfate content, and DPPH radical scavenging activity (55.94 $\pm 0.69 \%)$ [41]. In contrary to these findings, it is the $\mathrm{F}_{3}$ fraction of $S$. wightii that exhibited high contents and hence the activity. The current study was also supported by a report on the polysaccharide fraction from $S$. wightii which significantly reduced the proliferation of breast cancer cells (MCF7 and MDA-MB-231) in a dosedependent manner [42]. Whereas the fucoidan isolated from Padina boryana $(0.23 \%)$ containing $18.6 \%$ sulfates, exhibited $79 \%$ suppression of colony formation in human colon cancer cells DLD-1 at a concentration of $200 \mathrm{mg} \mathrm{mL}^{-1}$ [43], and the fucoidan from P. tetrastromatica with a yield of $8.18 \%$ and $0.7 \%$ sulfur showed a $50 \%$ reduction in the viability of HeLa cells at a concentration of $1.2 \mathrm{mg} \mathrm{mL}^{-1}$ [44]. The yield of fucoidan from $P$. tetrastromatica in the current study was comparatively higher $(4.28 \%)$ with $6.70 \pm 0.1 \%$ sulfates and exhibited maximum cytotoxicity of $40 \%$ at $200 \mathrm{mg} \mathrm{mL}^{-1}$ concentration. The difference observed clearly hints to the relation between sulfate content in fucoidan and its bioactivity. Although the ethanolic extract of P. gymnospora has been reported to contain a number of bioactives compared to many other algae, its sulfate content and antioxidant activity were found lower comparatively [45]. The antioxidant and FRSA of the methanolic extract of T. ornata are also already known [46]. The demand for seaweeds has enormously increased recently as it is a source of numerous bioactive compounds that are targeted for biomedical applications as well as the food industry [47]. In this scenario, the fucoidan extracted from the brown algae such as Sargassum and Padina, exhibiting good antioxidant and cytotoxic activities, is a promising candidate for various pharmaceutical applications.

\section{CONCLUSION}

We can say that this study demonstrated the antioxidant and cytotoxic potential of fucoidans from the three brown algae, S. wightii, P. tetrastromatica, and T. ornata from the coast of Kilakarai, Gulf of Mannar located in Southeast coast of Tamil Nadu, India. These fucoidans which comprise carbohydrates, uronic acid, and sulfate esters effectively scavenged free radicals. The solvent extracts also showed good antioxidant activity. As reported in some earlier studies, there was a positive correlation between the sulfate content and the bioactivity of fucoidans. This finding strengthens the existing attempts to elucidate the structure-function relations of fucoidan. Hence, these algae, its extracts, and fucoidans are found to be potential candidates for pharmacological applications. Further studies are required for the full-fledged utilization of this highly interesting biomolecule.

\section{ACKNOWLEDGMENTS}

The authors are thankful to the Director, Center for Advanced Studies in Botany for providing laboratory facilities. Further, we acknowledge the Department of Zoology, University of Madras; Indian Institute of Technology-Sophisticated Analytical Instrumentation Facility, Chennai;
Central leather research Institute, Chennai; and Amala Cancer Research Centre, Thrissur, Kerala, for rendering their services and support in carrying out this research work.

\section{AUTHORS' CONTRIBUTIONS}

Sreekala K. G conceived the project, collected and processed the samples, and performed analysis. Dr. Nagaraj Subramani supervised and guided the research work and preparation of the manuscript. All authors read and approved the final manuscript.

\section{CONFLICTS OF INTEREST}

All authors report no conflicts of interest regarding this manuscript.

\section{REFERENCES}

1. Wang ZJ, Zheng L, Yang JM, Kang Y, Park YD. Proteomic analyses for profiling regulated proteins/enzymes by Fucus vesiculosus fucoidan in B16 melanoma cells: A combination of enzyme kinetics functional study. Int J Biol Macromol 2018;112:667-74.

2. Balboa EM, Conde E, Moure A, Falqué E, Domínguez H. In vitro antioxidant properties of crude extracts and compounds from brown algae. Food Chem 2013;138 Suppl 2-3:1764-85.

3. Deniaud-Bouët E, Hardouin K, Potin P, Kloareg B, Hervé C. A review about brown algal cell walls and fucose-containing sulfated polysaccharides: Cell wall context, biomedical properties and key research challenges. Carbohydr Polym 2017;175:395-408

4. Sanjeewa KKA, Lee JS, Kim WS, Jeon YJ. The potential of brownalgae polysaccharides for the development of anticancer agents: An update on anticancer effects reported for fucoidan and laminaran. Carbohydr Polym 2017;177:451-9.

5. Wu L, Sun J, Su X, Yu Q, Yu Q, Zhang P, et al. A review about the development of fucoidan in antitumor activity: Progress and challenges. Carbohydr Polym 2016;154:96-111.

6. Omar HE, Eldien HM, Badary MS, Al-Khatib BY, Abd Elgaffar SK. The immunomodulating and antioxidant activity of fucoidan on the splenic tissue of rats treated with cyclosporine. A J Basic Appl Zool 2013;66 Suppl 5:243-54.

7. Ngo DH, Kim SK. Sulfated polysaccharides as bioactive agents from marine algae. Int J Biol Macromol 2013;62:70-5.

8. Dore CM, Alves MG, Will LS, Costa TG, Sabry DA, De Souza Rêgo LA, et al. A sulfated polysaccharide, fucans, isolated from brown algae Sargassum vulgare with anticoagulant, antithrombotic, antioxidant and anti-inflammatory effects. Carbohydr Polym 2013;91 Suppl 1:467-75.

9. Chen A, Lan Y, Liu J, Zhang F, Zhang L, Li B, et al. The structure property and endothelial protective activity of fucoidan from Laminaria japonica. Int J Biol Macromol 2017;105:1421-9.

10. Synytsya A, Bleha R, Synytsya A, Pohl R, Hayashi K, Yoshinaga K, et al. Mekabu fucoidan: Structural complexity and defensive effects against avian influenza A viruses. Carbohydr Polym 2014;111:633-44.

11. Phull AR, Majid M, Haq IU, Khan MR, Kim SJ. In vitro and in vivo evaluation of anti-arthritic, antioxidant efficacy of fucoidan from Undaria pinnatifida (Harvey) Suringar. Int J Biol Macromol 2017:97:468-80.

12. Phull AR, Kim SJ. Fucoidan as bio-functional molecule: Insights into the anti-inflammatory potential and associated molecular mechanisms. J Funct Foods 2017;38:415-26.

13. Sun Y, Hou S, Song S, Zhang B, Ai C, Chen X, et al. Impact of acidic, water and alkaline extraction on structural features, antioxidant activities of Laminaria japonica polysaccharides. Int J Biol Macromol 2018;112:985-95.

14. Yuan Y, Macquarrie D. Microwave assisted extraction of sulfated polysaccharides (fucoidan) from Ascophyllum nodosum and its antioxidant activity. Carbohydr Polym 2015;129:101-7.

15. Kadam SU, Tiwari BK, Smyth TJ, O'Donnell CP. Optimization of ultrasound assisted extraction of bioactive components from brown seaweed Ascophyllum nodosum using response surface methodology. Ultrason Sonochem 2015;23:308-16.

16. Nagao T, Kumabe A, Komatsu F, Yagi H, Suzuki H, Ohshiro T. Gene identification and characterization of fucoidan deacetylase for potential application to fucoidan degradation and diversification. J Biosci Bioeng 2017;124 Suppl 3:277-82.

17. Ale MT, Meyer AS. Fucoidans from brown seaweeds: An update on structures, extraction techniques and use of enzymes as tools for structural elucidation. RSC Adv 2013;3 Suppl 22:8131-41. 
18. Hifney AF, Fawzy MA, Abdel-Gawad KM, Gomaa M. Industrial optimization of fucoidan extraction from Sargassum sp. and its potential antioxidant and emulsifying activities. Food Hydrocoll 2016;54:77-88.

19. Ferlay J, Soerjomataram I, Dikshit R, Eser S, Mathers C, Rebelo M, et al. Cancer incidence and mortality worldwide: sources, methods and major patterns in GLOBOCAN 2012. Int J Cancer 2015;136 Suppl 5:E359-86.

20. Gutiérrez-Rodríguez AG, Juárez-Portilla C, Olivares-Bañuelos T, Zepeda RC. Anticancer activity of seaweeds. Drug Discov Today 2017;23 Suppl 2:434-47.

21. Suresh V, Senthilkumar N, Thangam R, Rajkumar M, Anbazhagan C, Rengasamy R, et al. Separation, purification and preliminary characterization of sulfated polysaccharides from Sargassum plagiophyllum and its in vitro anticancer and antioxidant activity. Process Biochem 2013;48 Suppl 2:364-73.

22. Dubois M, Gilles KA, Hamilton JK, Rebers PT, Smith F. Colorimetric method for determination of sugars and related substances. Anal Chem 1956;28 Suppl 3:350-6.

23. Dodgson K, Price R. A note on the determination of the ester sulphate content of sulphated polysaccharides Biochem J 1962;84 Suppl 1:106.

24. Bradford MM. A rapid and sensitive method for the quantitation of microgram quantities of protein utilizing the principle of protein-dye binding. Anal Biochem 1976;72 Suppl 1-2:248-54.

25. Dische Z, Shettles LB. A specific color reaction of methylpentoses and a spectrophotometric micromethod for their determination. J Biol Chem 1948;175 Suppl 2:595-603.

26. Vani T, Rajani M, Sarkar S, Shishoo C. Antioxidant properties of the ayurvedic formulation Triphala and its constituents. Int J Pharmacogn 1997;35 Suppl 5:313-7.

27. Eluvakkal T, Shanthi N, Murugan M, Arunkumar K. Extraction of antibacterial substances, galactofucoidan and alginate successively from the Gulf of Mannar brown seaweed Sargassum wightii Greville ex J. Agardh. Indian J Nat Prod Res 2014;5 Suppl 3:249-57.

28. Marudhupandi T, Kumar TT, Lakshmanasenthil S, Suja G, Vinothkumar T. In vitro anticancer activity of fucoidan from Turbinaria conoides against A549 cell lines. Int J Biol Macromol 2015;72:919-23.

29. Sinurat E, Rosmawaty P, Saepudin E. Characterization of fucoidan extracted from binuangeun's brown seaweeds. Int J Chem Environ Biol Sci 2015;3:329-32.

30. Delma CR, Somasundaram ST, Srinivasan GP, Khursheed M, Bashyam MD, Aravindan N. Fucoidan from Turbinaria conoides: A multifaceted 'deliverable' to combat pancreatic cancer progression. Int J Biol Macromol 2015;74:447-57.

31. Thuy TT, Van TT, Hidekazu Y, Hiroshi U. Fucoidan from Vietnam Sargassum swartzii: Isolation, Characterization and Complexation with Bovine Serum Albumin. Asian J Chem 2012;24 Suppl 8:3367-70.

32. Vasquez RD, Ramos JD, Bernal SD. Chemopreventive properties of sulfated polysaccharide extracts from Sargassum siliquosum JG Agardh (Sargassaceae). Int J Phar Bio Sci 2012;3:333-45.

33. Wang CY, Chen YC. Extraction and characterization of fucoidan from six brown macroalgae. J Mar Sci Technol 2016;24 Suppl 2:319-28.
34. Yang WN, Chen PW, Huang CY. Compositional characteristics and in vitro evaluations of antioxidant and neuroprotective properties of crude extracts of fucoidan prepared from compressional puffing-pretreated Sargassum crassifolium. Mar Drugs 2017;15 Suppl 6:183.

35. Wang CY, Wu TC, Hsieh SL, Tsai YH, Yeh CW, Huang CY. Antioxidant activity and growth inhibition of human colon cancer cells by crude and purified fucoidan preparations extracted from Sargassum cristaefolium. J Food Drug Anal 2015;23 Suppl 4:766-77.

36. Cunha L, Grenha A. Sulfated seaweed polysaccharides as multifunctional materials in drug delivery applications. Mar Drugs 2016; $14: \mathrm{e} 42$

37. Syad AN, Shunmugiah KP, Kasi PD. Antioxidant and anti-cholinesterase activity of Sargassum wightii. Pharm Biol 2013;51:1401-10

38. Suresh V, Kumar NS, Murugan P, Palani P, Rengasamy R, Anbazhagan C. Antioxidant properties of sequential extracts from brown seaweed, Sargassum plagiophyllum, C. Agardh. Asian Pac J Trop Dis 2012;2:S937-9.

39. Anjana A, Ahamed KN, Ravichandiran V, Sumithra M, Anbu J. Anticancer activity of Sargassum wightii Greville on Dalton's ascitic lymphoma. Chin J Nat Med 2014;12 Suppl 2:114-20.

40. Dhinakaran DI, Geetha P, Rajalakshmi J. Antioxidant activities of marine algae Valoniopsis pachynema and Sargassum swartzii from the Southeast coast of India. Int J Fish Aquat Stud 2015;3:426-30.

41. Palanisamy S, Vinosha M, Manikandakrishnan M, Anjali R, Rajasekar P, Marudhupandi T, et al. Investigation of antioxidant and anticancer potential of fucoidan from Sargassum polycystum. Int J Biol Macromol 2018;116:151-61.

42. Vaikundamoorthy R, Krishnamoorthy V, Vilwanathan R, Rajendran R. Structural characterization and anticancer activity (MCF7 and MDAMB-231) of polysaccharides fractionated from brown seaweed Sargassum wightii. Int J Biol Macromol 2018;111:1229-37.

43. Usoltseva RV, Anastyuk SD, Ishina IA, Isakov VV, Zvyagintseva TN, Thinh PD, et al. Structural characteristics and anticancer activity in vitro of fucoidan from brown alga Padina boryana. Carbohydr Polym 2018;184:260-8.

44. Jose GM, Raghavankutty M, Kurup GM. Sulfated polysaccharides from Padina tetrastromatica induce apoptosis in hela cells through ROS triggered mitochondrial pathway. Process Biochem 2018;68:197-204.

45. Rajasekar T, Shamya AM, Joseph J. Screening of phytochemical, antioxidant activity and antibacterial activity of marine seaweeds. Int J Pharm Pharm Sci 2019;11 Suppl 1:61-6.

46. Dhanraj V, Manivasagam T, Karuppaiah J. Myricetin isolated from Turbinaria ornata ameliorates rotenone induced Parkinsonism in Drosophila melanogaster. Int J Pharm Pharm Sci 2017;9 Suppl 11:39-44.

47. Ashwini S, Babu TV, Saritha, Shantaram M. Seaweed extracts exhibit anticancer activity against HeLa cells lines. Int J Curr Pharm Res 2017;9 Suppl 1:114-7. 